\title{
Glycans of SARS-CoV-2 Spike Protein in Virus Infection and Antibody Production
}

\author{
Xiaohui Zhao ${ }^{\dagger}$, Huan Chen ${ }^{\dagger}$ and Hongliang Wang * \\ Department of Pathogen Biology and Immunology, Xi'an Jiaotong University Health Science Center, Xi'an, China
}

\section{OPEN ACCESS}

Edited by:

James A. Garnett,

King's College London,

United Kingdom

Reviewed by:

Emilia Pedone,

Institute of Biostructure and

Bioimaging, Italy

Fred Robert Naider,

College of Staten Island, United States

*Correspondence:

Hongliang Wang

hongliangwang@xjtu.edu.cn

${ }^{\dagger}$ These authors contributed equally to this work

Specialty section:

This article was submitted to

Structural Biology,

a section of the journal

Frontiers in Molecular Biosciences

Received: 16 November 2020

Accepted: 22 January 2021

Published: 13 April 2021

Citation:

Zhao X, Chen H and Wang H (2021) Glycans of SARS-CoV-2 Spike Protein in Virus Infection and Antibody Production.

Front. Mol. Biosci. 8:629873. doi: $10.3389 /$ fmolb.2021.629873
Viral protein glycosylation represents a successful strategy employed by the parasite to take advantage of host-cell machinery for modification of its own proteins. The resulting glycans have unneglectable roles in viral infection and immune response. The spike (S) protein of severe acute respiratory syndrome coronavirus 2 (SARS-CoV-2), which presents on the surface of matured virion and mediates viral entry into the host, also undergoes extensive glycosylation to shield it from the human defense system. It is believed that the ongoing COVID-19 pandemic with more than 90,000,000 infections and $1,900,000$ deaths is partly due to its successful glycosylation strategy. On the other hand, while glycan patches on S protein have been reported to shield the host immune response by masking "nonself" viral peptides with "self-glycans," the epitopes are also important in eliciting neutralizing antibodies. In this review, we will summarize the roles of S protein glycans in mediating virus-receptor interactions, and in antibody production, as well as indications for vaccine development.

Keywords: SARS-CoV-2 (2019-nCoV), vaccine, glycosylation, structure, viral entry

\section{INTRODUCTION}

Since its first emergence in December 2019, it only took several months before the novel coronavirus disease 2019 (COVID-19), a severe respiratory illness, was declared as a pandemic by the World Health Organization (https://www.who.int/docs/default-source/coronaviruse/situation-reports/ 20200311-sitrep-51-covid-19.pdf?sfvrsn=1ba62e57_10). The causative agent was identified to be a member of Betacoronavirus and termed as SARS-CoV-2 (Coronaviridae Study Group of the International Committee on Taxonomy of Viruses, 2020). Coronaviruses (CoVs) are enveloped positive-sense RNA viruses, and as a virus with an RNA genome, CoVs have high mutation rates and hence are believed to alter host range and tissue tropism efficiently (Li, 2016; Cui et al., 2019; Hu et al., 2020). CoVs are responsible for multiple respiratory disorders of varying severity in humans (Cui et al., 2019). Seven coronavirus strains are known to cause human infection; among them, $\mathrm{HCoV}$ 229E, HCoV NL63, HCoV HKU1, and HCoV OC43 typically cause only mild upper respiratory diseases in immunocompetent hosts, although some of them can cause severe infections in infants, young children, and elderly individuals (Cui et al., 2019), while severe acute respiratory syndrome coronavirus (SARS-CoV), Middle East respiratory syndrome coronavirus (MERS-CoV), and SARSCoV-2 cause severe respiratory illness and fatalities (Cui et al., 2019; Hasöksüz et al., 2020).

The spike protein $(S)$ of coronavirus, which forms large protrusions from the virus surface and gives the virus the appearance of having crowns, mediates virus entry into host cells (Hu et al., 2020; Cui et al., 2019; Hasöksüz et al., 2020; Virology, 1968). Therefore, the S protein is a critical determinant of viral host and tissue tropism. In addition, the $\mathrm{S}$ protein is glycosylated by the host 
cellular glycosylation apparatus as it passes through the secretory pathway. These glycans confer two benefits on the virus. First, the mannose residues within these glycans are important moieties to interact with cell surface attachment factors, like glycosaminoglycans (GAGs) and sialic acid-containing oligosaccharides (Li et al., 2017; Tortorici et al., 2019; Robson, 2020), before binding to the high-affinity receptor-in the case of SARS-CoV-2, angiotensin-converting enzyme 2 (ACE2) (Hoffmann et al., 2020; Zhou et al., 2020). In the complex of spike-ACE2, extensive glycosylation at the interface of the complex was reported (Zhao et al., 2020), highlighting roles for glycans in modulating spike-ACE2 interactions. Second, glycans sterically mask the underlying polypeptide epitopes from recognition of potentially neutralizing antibodies, and thus sometimes referred to as the "glycan shield" (Doores, 2015; Bagdonaite and Wandall, 2018). Viral glycoproteins are the main targets of host antibodies, as these molecules are prominently displayed on the virion surfaces (Murin et al., 2019). Different from bacteria, in which glycans are encoded by the bacterial genome and are treated as "nonself" epitopes by corresponding hosts, viruses take advantage of host cell machinery for glycosylation and generally are decorated with the "self"-glycans. These "self"-glycans are generally thought to be a strategy to escape the host immune response (Wang, 2020). For example, human immunodeficiency virus (HIV-1) (StewartJones et al., 2016), hepatitis C virus (Falkowska et al., 2007), and Ebola virus (Iraqi et al., 2020) exhibit extensive N-linked glycans that cover some of the critical virus-neutralizing epitopes to block antibody recognition. Similarly, coronavirus S glycans also mask the protein surface and consequently limit antibody access to protein-neutralizing epitopes (Grant et al., 2020; Wang, 2020; Watanabe et al., 2020). Therefore, understanding the glycosylation of $\mathrm{S}$ protein has important implications in viral pathobiology and vaccine design.

In addition to $S$ protein, glycosylation of $E$ protein, $M$ protein, and nonstructural proteins in SARS-CoV has also been predicted, and their potential roles are discussed in a review (Fung Liu, 2018). In this review, we will mainly focus on the glycosylation of $\mathrm{S}$ protein.

\section{Spike Protein and Glycosylation}

The $S$ protein, which is conserved to various degrees across the Coronaviridae family, is the most critical structural protein of SARS-CoV-2. It forms homotrimers and protrudes from the viral surface (Figure 1A), which makes the virus reminiscent of the solar corona, and it plays a key role in the virus entry into the host cell (Hasöksüz et al., 2020; Virology, 1968; Wrapp et al., 2020).

The $S$ protein is a type I membrane protein, synthesized in the endoplasmic reticulum, and is transported to the plasma membrane (Bosch et al., 2003). For SARS-CoV-2, the total length of $S$ is 1,273 amino acids and consists of a signal peptide located at the $\mathrm{N}$-terminus. It has been reported that $\mathrm{S}$ of SARS-CoV-2 contains a furin cleavage site, which contains multiple basic amino acids (PRRAR) and can be cleaved into two functional subunits: $\mathrm{S} 1$ subunit, which is responsible for binding to cellular receptor; and S2 subunit, which functions to fuse the viral and cellular membranes (Hoffmann et al., 2020; Walls et al., 2020; Xia et al., 2020). After cleavage, both subunits remain noncovalently bound in the prefusion conformation (Wrapp et al., 2020; Walls et al., 2020; Kirchdoerfer et al., 2016). In contrast, S of SARS-CoV and other SARS-related coronaviruses (SARSrCoVs), particularly RaTG13, which has 96\% identity of its genomic sequence to that of SARS-CoV-2, does not contain a furin-like motif (Xia et al., 2020) (Figure 1B). The function of this cleavage site is being extensively studied (Johnson et al., 2020; Walls et al., 2020; Xia et al., 2020).

Structures of S from other Betacoronavirus have shown that the receptor-binding domain $(\mathrm{RBD})$ of $\mathrm{S} 1$ undergoes hinge-like conformational movements that transiently hide or expose the determinants of receptor binding (Gui et al., 2017; Pallesen et al., 2017; Yuan et al., 2017). The "closed" conformation is three-fold symmetric and has all three RBDs in "down" positions. In this conformation, RBD is not receptor-accessible due to steric clashes, while the "open" conformation is asymmetric, in which at least one RBD is in an "up" position and is used for receptor binding (Gui et al., 2017; Yuan et al., 2017). The 3D structure of SARS-CoV-2 S trimer in the prefusion conformation has also been determined by cryo-EM (Walls et al., 2020; Wrapp et al., 2020). Overall, the SARS-CoV-2 S ectodomain is a $160-\mathrm{A}^{\circ}$ long trimer with a triangular cross section (Walls et al., 2020). And similar to SARS-CoV S, a single RBD was observed in the "up" position in the prefusion state for receptor binding, with the other two RBDs in the "down" position (Walls et al., 2020; Wrapp et al., 2020; Figure 2A).

Another key feature of the $S$ protein is its extensive glycosylation which depends on the host glycosylation machinery. Depending on the acceptor amino acid atom to which the sugar moiety is attached, glycosylation can be divided into N-linked glycosylation (sugars are attached to the amide nitrogen atom in the side chain of asparagine) and O-linked glycosylation (sugars are attached to the oxygen atom in the side chain of serine or threonine) (Berg et al., 2002; Bagdonaite and Wandall, 2018). An asparagine residue can accept an oligosaccharide only if the residue is part of an Asn$\mathrm{X}$-Ser or Asn-X-Thr sequence, in which $\mathrm{X}$ can be any residue except proline (Breitling and Aebi, 2013). In contrast, there are no conserved protein sequence motifs for general or isoform-specific $\mathrm{O}$-glycosylation, and therefore it is much more difficult to predict this modification (Gerken et al., 2011; Bagdonaite and Wandall, 2018). O-glycans have also been observed on some viral proteins and have been suggested to play roles in the biological activity of viral proteins (Bagdonaite and Wandall, 2018; Andersen et al., 2020).

The monomer of the SARS-CoV-2 S protein comprises $22 \mathrm{~N}$-linked glycosylation sequons. Walls et al. first resolved 16 of them with oligosaccharides with cryo-EM (Walls et al., 2020). Later on, by using a site-specific mass spectrometric (MS) approach, Watanabe et al. proved that all sites are glycosylated, and they further analyzed the glycosylation pattern of these 22 sites and found that two sites on SARS-CoV-2 S are principally oligomannose-type (least processed): N234 and N709. A mixture of oligomannose- and complex-type (most processed) glycans can be found at sites N61, N122, N603, N717, N801, and N1074, 


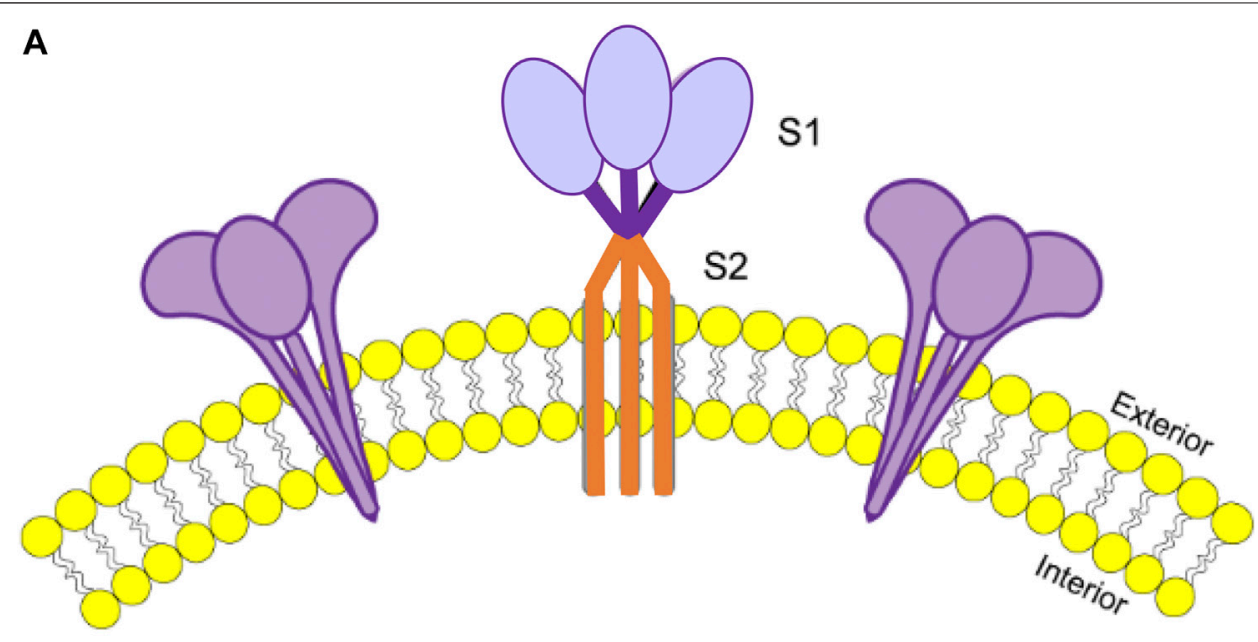

B
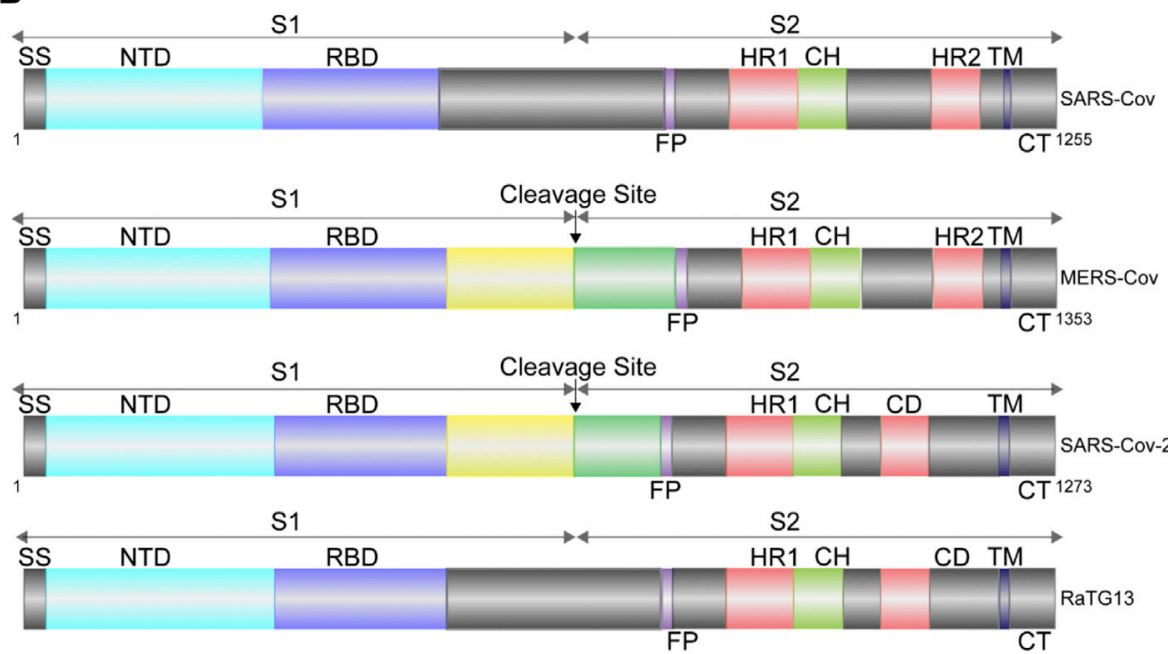

FIGURE 1 | Cartoon representation of S protein structures. (A). Diagram of S protein trimers on viral envelope (yellow: lipid bilayer). (B). Diagram showing the domain organization of the S proteins of SARS-CoV, MERS-CoV, RaTG13 and SARS-CoV-2. MERS-CoV and SARS-CoV-2 can be cleaved into S1 and S2 by cellular protease, while SARS-CoV and RaTG13 cannot. SS, signal sequence; RBD, receptor-binding domain; FP, fusion peptide; HR1, heptad repeat 1; CH, central helix; CD, connector domain; HR2, heptad repeat 2; TM, transmembrane domain; CT, cytoplasmic tail.

while the remaining sits have complex glycans (Virology, 1968) (Figure 2B). Zhao et al. also reported the site-specific N-linked microheterogeneity with similar results and suggested that these glycans sterically masked polypeptide epitopes and directly modulated spike-ACE2 interactions (Zhao et al., 2020).

In addition to the MS-based approaches that investigate the global glycoprofile of the protein, Lenza et al. characterized the glycan structures of $\mathrm{N}$-linked glycan in the RBD using nuclear magnetic resonance (NMR) spectroscopy (Lenza et al., 2020). Compared to MS, NMR avoids sample digestions, thus providing glycan information of the intact protein in a physiological-like solution. For example, the importance of $\mathrm{N}$-acetylgalactosylation and hyper-fucosylation at the terminal chains of the RBD
$\mathrm{N}$-glycans was revealed, and novel glycan motifs, such as 4SulLDN, 6'SLDN, LeX, and LDNF, were identified by the NMR-based study (Lenza et al., 2020).

In contrast to the consistent results of $\mathrm{N}$-linked glycosylation, different groups have reported different O-linked glycosylation patterns of $S$ protein depending on different protein expression systems and detection methods employed. Shajahan et al. reported a high level of O-glycosylation of S1 and S2 when expressed independently, and detected O-glycosylation at sites Thr323 and Ser325 on the S1 subunit of the S protein (Shajahan et al., 2020). However, other two reports detected low occupancy at most sites of O-glycan modification using $\mathrm{S}$ trimer for analysis (Watanabe et al., 2020; Zhao et al., 2020). One possible 


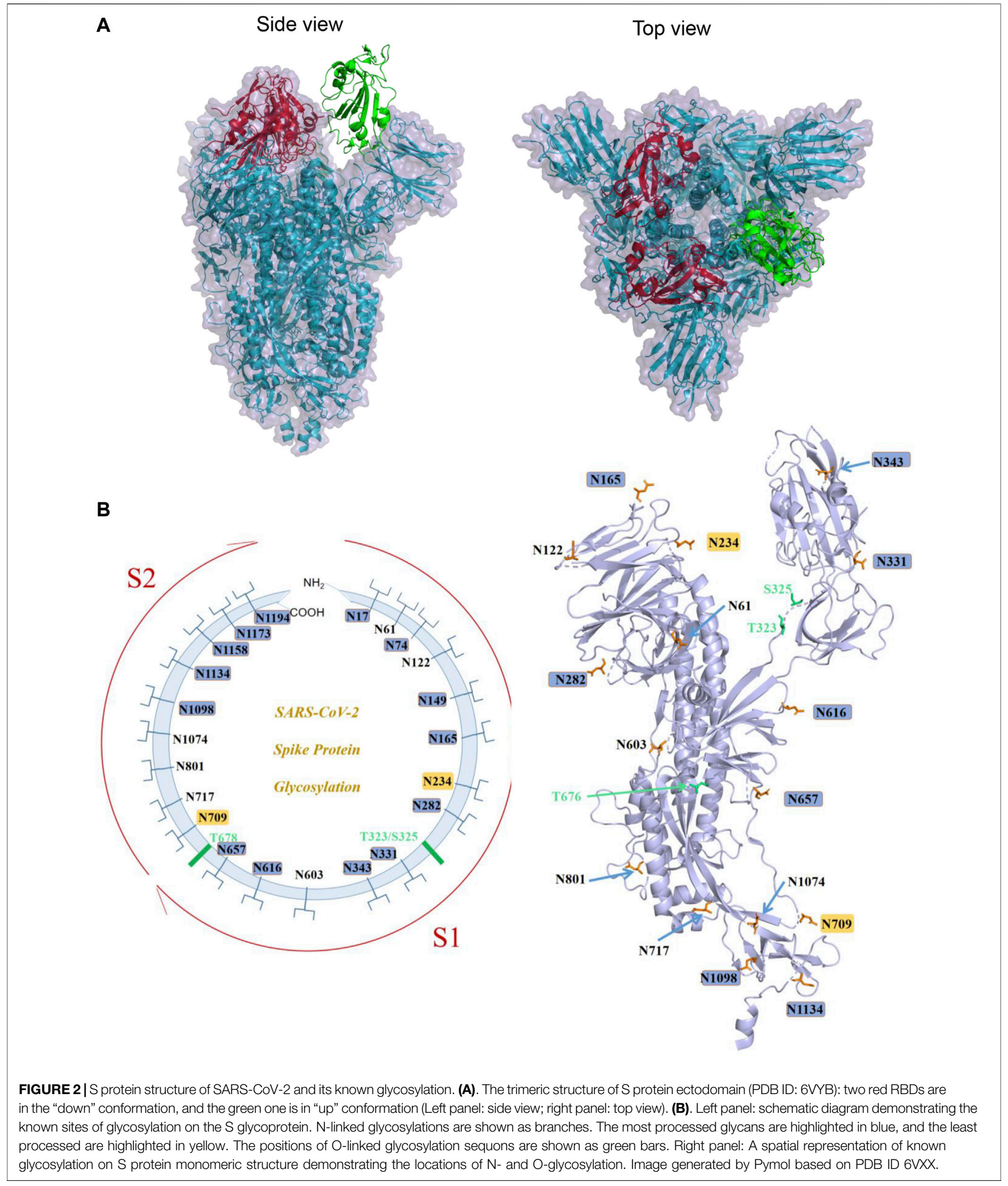

explanation for this discrepancy is that the $\mathrm{S}$ protein could undergo different types of glycosylation at different conformations or oligomeric states. In addition, Andersen et al. predicted a unique O-linked glycosylation pattern flanking the furin cleavage site (Andersen et al., 2020), and glycosylation around this cleavage site is thought to regulate the activation of the $S$ 
protein. Sanda et al. confirmed this O-glycosylation near the furin cleavage site (T678) using MS-based methods; in addition, they identified another eight O-glycopeptides (Sanda et al., 2020). The functional role of most of the O-linked glycosylation is not fully understood.

\section{Glycans in Viral Entry}

Glycans on viral envelope glycoproteins play important roles in virus infection, with specific functions identified in various stages of viral infection (Bagdonaite and Wandall, 2018). But, in general, most of the function falls into the stage of viral entry and release. To date, as few studies have been conducted on the role of glycans in SARS-CoV-2 release; here in this review, we will focus on their roles in viral entry. Viral entry into host cells is initiated by the interaction of virion with cell surface attachment factors. And host cell glycans often serve as the front lines of initial contacts to facilitate following high-affinity binding to virus-specific receptors (Watanabe et al., 2019; Koehler et al., 2020). In addition, some cell surface glycans also function as coreceptors or specific entry receptors (Raman et al., 2016). Therefore, glycans from both the viral glycoprotein and host cell surface are involved in viral attachment and are critical for efficient viral entry.

Similarly, SARS-CoV-2 also exploited this low-to-high-affinity strategy for efficient viral attachment and entry. S protein was able to bind heparan sulfate or sialic acids to initiate the attachment (Baker et al., 2020; Hao et al., 2020; Liu et al., 2020). On the other hand, many coronaviruses have a galectin-like domain in the $\mathrm{N}$-terminal domain (NTD) of S1, which functions as viral lectins to bind cell surface sugars, like 5-N-acetyl-9-O-acetylneuraminic acid (Peng et al., 2011; Peng et al., 2012). Meanwhile, a similar ganglioside-binding domain is found in the NTD of SARS-CoV-2 S protein. In the spike trimers, the $\mathrm{RBD}$ locates at the center, while the NTD lies laterally, enabling the ganglioside-binding domain to interact with the large area of lipid rafts on cell surface (Fantini et al., 2020). Together, these low-affinity interactions may facilitate virus binding to the high-affinity receptor ACE2.

The structure of the complex of ACE2 and RBD of S has recently been determined by cryo-EM (Yan et al., 2020) and X-ray crystallography (Lan et al., 2020; Figure 3A). The overall complex structure showed that ACE2 has two lobes, and RBD contacts the bottom side of the small lobe of ACE2. The key residues in the SARS-CoV-2 RBD and ACE2 binding are highly conserved or share similar side chain properties with those in the SARS-CoV RBD (Yan et al., 2020; Lan et al., 2020; Figure 3B). In addition, the cryo-EM results also suggested that ACE2 formed heterodimer, in which they might simultaneously bind to two S protein trimers (Lan et al., 2020).

Extensive glycosylation has also been characterized at the interface of S and ACE2 interaction (Zhao et al., 2020; Watanabe et al., 2020; Casalino et al., 2020). As mentioned earlier, glycans of viral surface protein may shield the protein from molecular recognition (Figure 4A). However, to effectively function, the $S$ RBD region must be fully exposed and accessible to bind ACE2 receptor to initiate infection. By using all-atom molecular dynamic simulation (MD), two N-glycan sites adjacent to the RBD (N165 and N234) were predicted to function at the interface of ACE2 interaction (Casalino et al., 2020). Further analysis showed that the "down" conformation of RBD has a remarkably larger coverage of glycans than that of RBD in "up" conformations (Casalino et al., 2020), indicating the virus has evolved mechanisms for receptor recognition and effective infection (Figure 4B, left panel). Unexpectedly, N165A and $\mathrm{N} 234 \mathrm{~A}$ mutations, which led to glycan deletions at the respective sites, were shown to have reduced binding to ACE2 receptor (Casalino et al., 2020), suggesting that these glycans are actually important for the conformational plasticity of the RBD and hence ACE2 interaction. Consistent with this, Watanabe et al. also observed glycosylation on these sites (Watanabe et al., 2020), and this shielding of receptor binding sites by glycans is a common feature of viral glycoproteins, as observed on other viruses (Zhao et al., 2020). In addition, glycans on ACE2 molecules are also important for the virus-receptor interaction. For example, two glycans on ACE2 (at N090 and $\mathrm{N} 322$ ) can form interactions with the $\mathrm{S}$ protein, of which the N322 glycan interaction with the $S$ trimer is outside of the RBD, while the N090 glycan is close to the S trimer surface (Zhao et al., 2020). Non-synonymous single-nucleotide polymorphisms (SNPs) in the ACE2 glycosylation site have been reported in the human population and proposed to alter ACE2-S protein interaction (Zhao et al., 2020), and thus might affect the viral infection progress and severity of the disease. Last, intermolecular glycan-glycan interactions are also observed between the glycans of ACE2 and those in the S protein (Zhao et al., 2020). These glycan-mediated interactions are vital for efficient viral infection.

\section{Glycans in Antibody Production}

During the battle against pathogen infections, our immune system has developed sophisticated mechanisms to identify and eliminate invading pathogens, including viruses. In turn, viruses have also evolved mechanisms to counteract or take advantage of the host's defense mechanisms (Finlay and McFadden, 2006; Rouse and Sehrawat, 2010). Glycans on viral glycoproteins have dual roles in virus-host interplay. On the one hand, glycans can be part of the immune determinants themselves, but on the other hand, glycans can mask the antigenic protein epitopes from recognition (Bagdonaite and Wandall, 2018). For most CoVs, S is virtually the only antigen present at the virus surface, it is the major target for host antibodies, and this viral antigen is therefore a main target for vaccine development (Conte et al., 2020). A comprehensive SARS-CoV-2 S protein immunogen-induced antibody signature study found that although S, S1, S2, and RBD all can elicit antibody, RBD immunogen elicited a higher antibody titer with higher affinity (Ravichandran et al., 2020), this is in consistent with the fact that RBD is the most exposed epitope of S (Grant et al., 2020). And due to the sequence conservation, one might expect SARS-CoV S to elicit cross-reactive antibody against SARS-CoV-2 (Ou et al., 2020; Pinto et al., 2020; Walls et al., 2020). However, certain existing monoclonal antibodies raised against the SARS-CoV RBD (S230, m396, and 80R) failed to bind the RBD of SARS-CoV-2 S (Lan et al., 2020; Wrapp et al., 2020), reflecting a divergence of antigenic epitopes among different CoVs. 


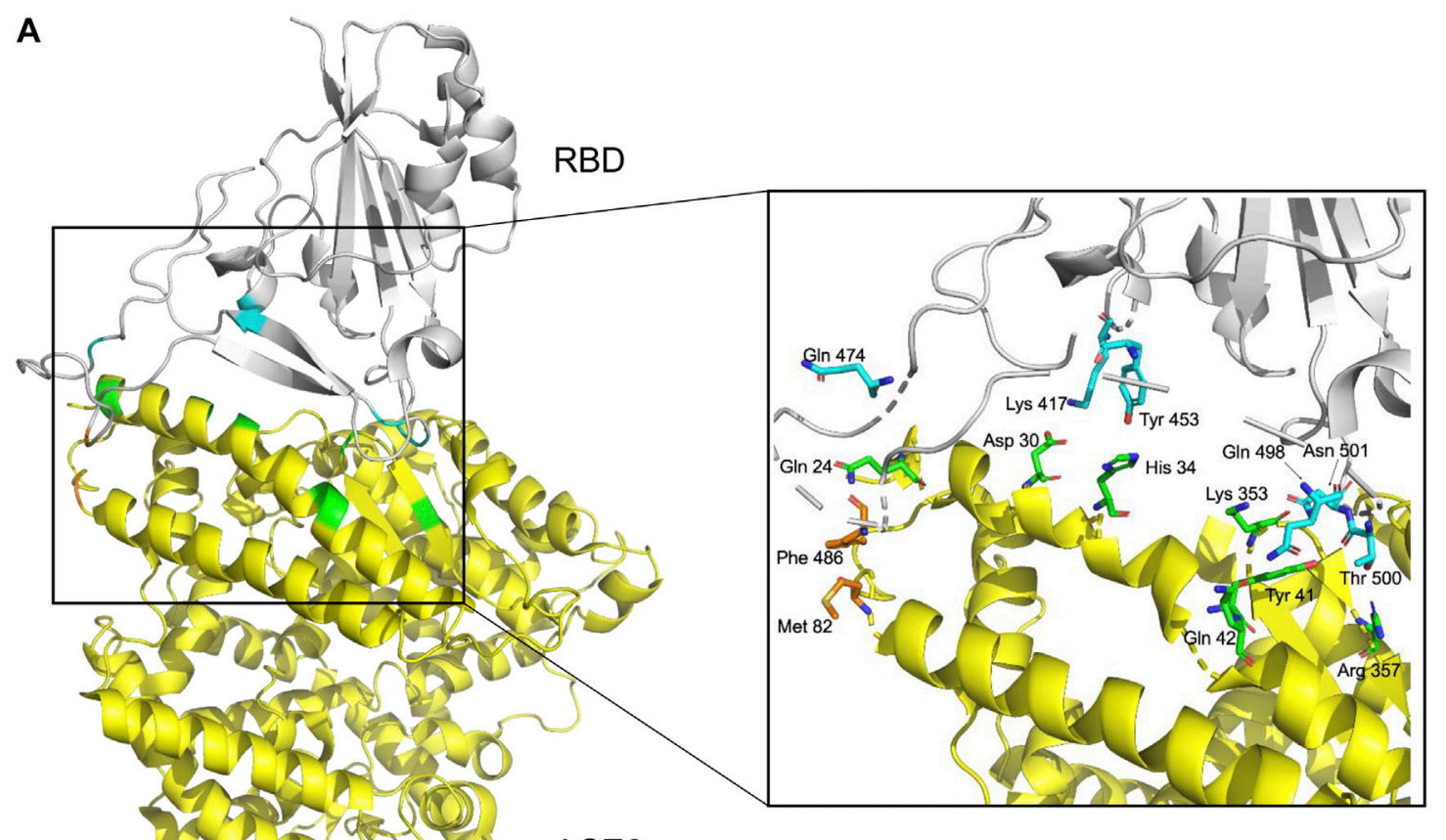

ACE2
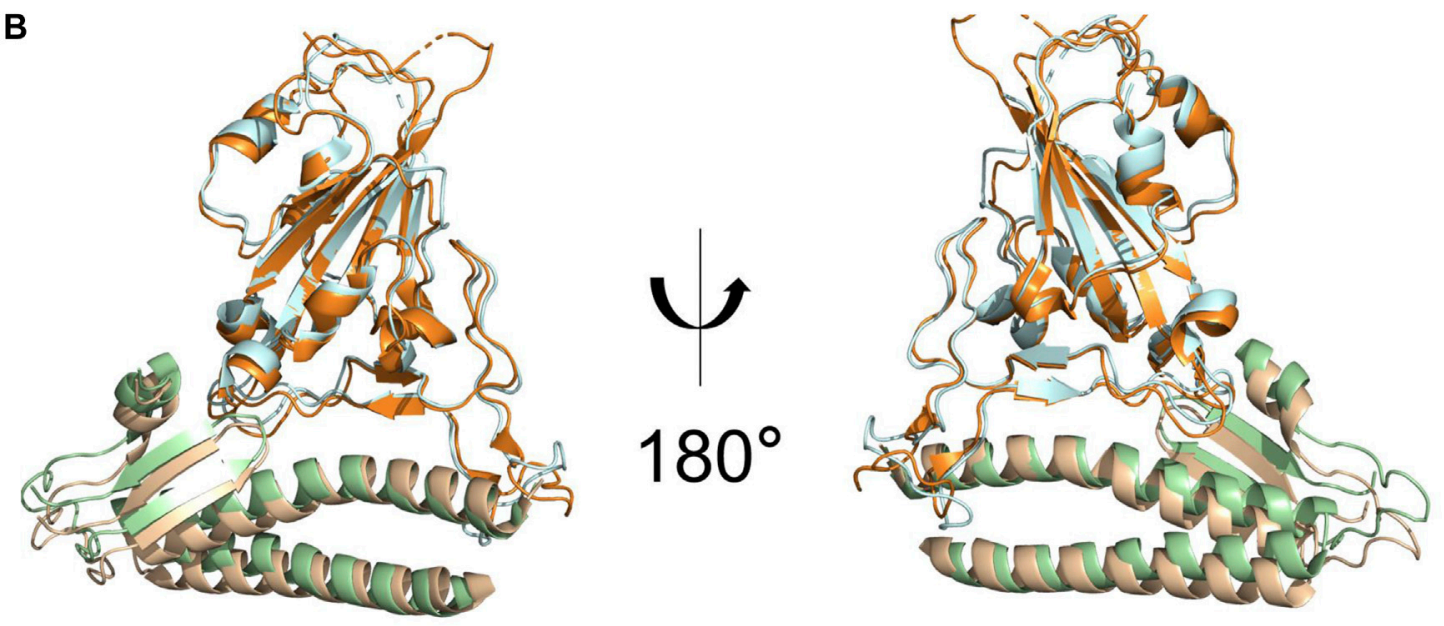

FIGURE 3 | S protein and ACE2 receptor interaction. (A). The complex structure of RBD-ACE2 demonstrating the interactions between SARS-CoV-2 RBD (gray) and ACE2 (yellow) with key residues on RBD and ectodomain of ACE2 shown in blue and green, respectively. Images generated based on PDB 6MOJ. (B). Structural superimpose of the SARS-CoV-2-RBD/ACE2 and SARS-CoV-RBD/ACE2 complexes. SARS-CoV-RBD and ectodomain of ACE2 are colored in cyan and green, respectively. SARS-CoV interactions were generated based on PDB 2AJF.

\section{Glycan as Shield}

As $\mathrm{S}$ is highly glycosylated, one would predict that glycan shielding is important in immune evasion. MD simulations predicted that $S$ antigen was covered with glycans that will shield antibody recognition (Figures 4A,B left panel). Depending on the glycoforms, the exposed surface area is between 53 and $71 \%$, and the most exposed epitopes, as expected, comprise the RBD that interacts with ACE2 (Grant et al., 2020). Compared to $S$ proteins of MERS-CoV and SARS-
$\mathrm{CoV}$, and viral envelope glycoproteins of HIV-1, SARS-CoV-2 S is less densely glycosylated (Behrens et al., 2016; Walls et al., 2019; Grant et al., 2020; Watanabe et al., 2020), suggesting the protein surface is more exposed and may elicit humoral immunity more efficiently. Beyond a role in shielding the underlying protein from recognition by antibodies, the glycans may also attenuate the T-cell response. For example, it has been reported that some glycans in S may interfere with antigen presentation in an HLA complex (Grant et al., 2020). 

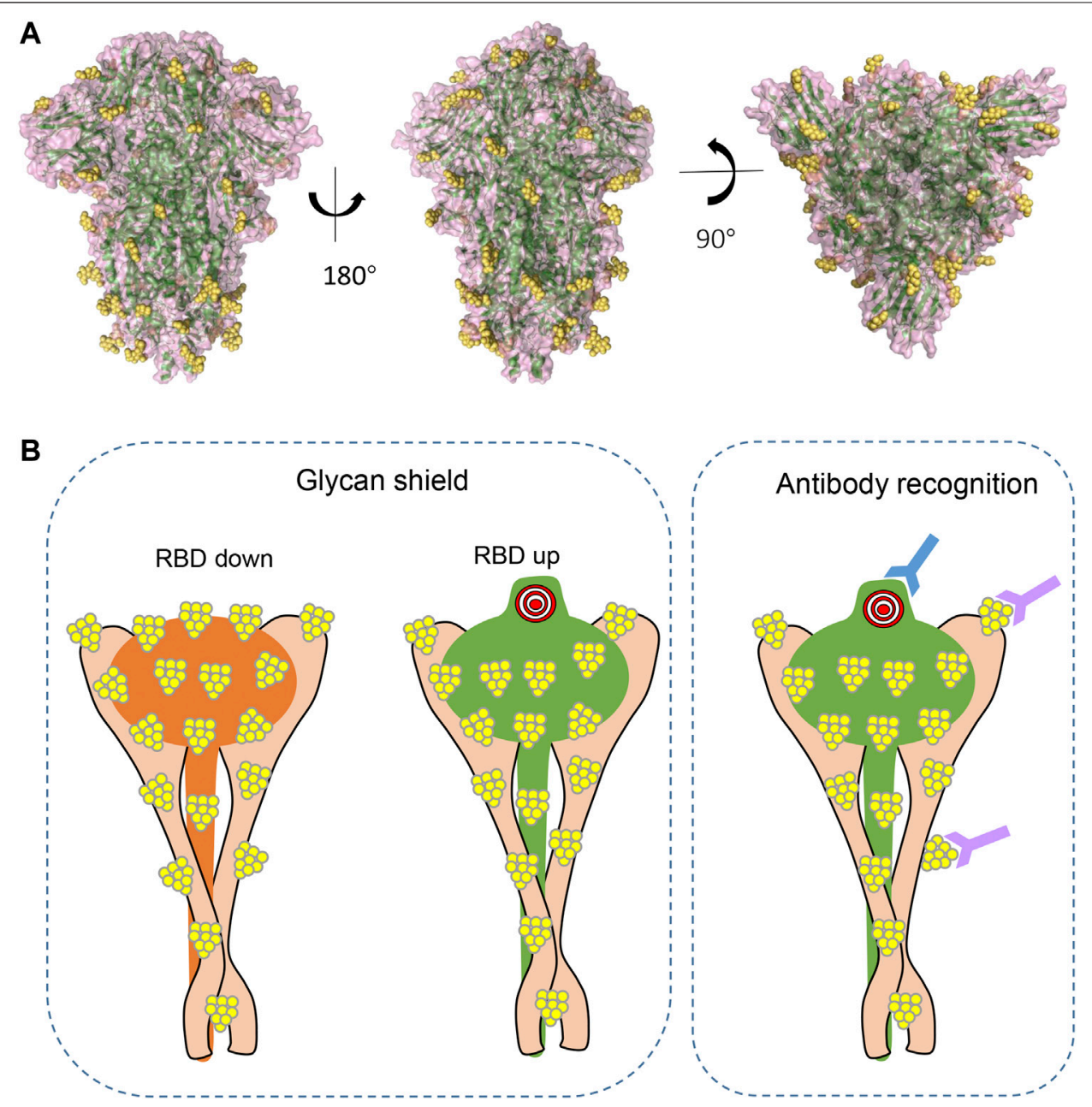

FIGURE 4 | The shielding effect of glycosylation on the S protein trimer (A). Structural representations from different views demonstrating glycan epitopes. Yellow balls represent glycans, and S backbone was generated based on PDB ID: 6VXX. (B). Diagram of glycans in molecular recognition shielding and their potential role in antibody elicitation (left panel: compared to RBD in "up" position, RBD in "down" position has larger coverage of glycan; right panel: in addition to peptide epitopes, some glycans can also be recognized by antibody and are thus important epitopes in antibody production).

\section{Glycan as Epitopes}

The high density of glycans creates a shield that blocks antibody recognition, but some of the most potent and broadly neutralizing antibodies are able to recognize these glycan epitopes (Doores, 2015) (Figure 4B, right panel). A recent study has shown that glycan clusters on viral proteins are different from those of host protein glycosylation (Wang et al., 2015), making them good candidates for immune response induction. In fact, $2 \mathrm{G} 12$, isolated from the serum of an HIV-positive individual, was the first reported broad neutralizing antibody to bind to carbohydrates (a1->2 mannose) on HIV gp120 (Buchacher et al., 1994; Trkola et al., 1996; Scanlan et al., 2002). In addition to these mannose patch-targeted antibodies, antibodies recognizing complex-type glycans have also been reported against HIV glycoprotein (Mouquet et al., 2012; Pancera et al., 2013; Falkowska et al., 2014). In addition, broadly neutralizing antibodies with epitopes comprising glycans have also been characterized against dengue virus E protein (Rouvinski et al., 2015), all these suggesting that glycans are important moieties to elicit broadly neutralizing antibodies. The SARS-CoV-2-S comprises 22 N-linked glycosylation sites with different glycoforms, and some of them may also elicit neutralizing antibodies. In fact, a recent study showed that one antibody, that is, S309, which potently neutralizes both SARS-CoV and SARS-CoV-2, actually recognizes an epitope containing a glycan that is conserved within the Sarbecovirus subgenus (Pinto et al., 2020), suggesting that glycans in SARS-CoV-2 are important in neutralizing antibody production. Whether other glycans are antigenic and could elicit neutralizing antibodies need further investigation.

\section{Glycans and Autoimmunity}

Glycans in the glycoprotein could stimulate the production of carbohydrate-specific antibodies, which play important roles in protecting the host from infectious disease. On the other hand, they might also cross-react with host antigens, leading to autoimmune diseases (Patel and Kearney, 2016; Kappler and 
Hennet, 2020). Previous studies have demonstrated that autoimmune diseases, like Guillain-Barre syndrome, multiple sclerosis, and inflammatory bowel disease, are caused by carbohydrate-specific antibodies related to bacterial infection or gut microbes (Kappler and Hennet, 2020). A recent SARSCoV-2 study showed that COVID-19 patients have unusually high IgM and IgG antibodies to self-carbohydrates, including gangliosides, $\mathrm{N}$-linked glycans, LacNAc derivatives, blood group H1, and sialyl Lewis X (Butler and Gildersleeve, 2020), indicating the possibility of autoimmune disorders caused by these antibodies. Noteworthily, many of the glycan antibodies are naturally occurring antibodies and are detectable in the absence of deliberate immunization or vaccination (Kappler and Hennet, 2020), and these antibodies are low in affinity and specificity; therefore, their roles in SARS-CoV-2 patient autoimmunity remain unclear.

\section{Glycans in Vaccine Development}

Many efforts have been directed toward the development of the vaccines against SARS-CoV-2. Due to its high antigenicity and ability to elicit neutralizing antibodies in convalescent individuals (Cao et al., 2020; Ju et al., 2020), S protein is an ideal candidate for vaccine development. Currently, dozens of vaccine candidates based on $\mathrm{S}$ or its subunits are in rapid development (Sternberg and Naujokat, 2020), be it delivered by the recombinant protein, DNA, mRNA, or viral vector-based form. Among these vaccine types, mRNA vaccines have shown great potential and offered advantages over conventional vaccines. A recent study showed that a single immunization of SARS-CoV-2 mRNA vaccine elicited potent germinal center responses and neutralizing antibody production, in contrast to the poor performance of recombinant protein vaccine (Lederer et al., 2020). The fact that different forms of S protein would have different glycosylation patterns (Brun et al., 2020; Watanabe et al., 2020) suggests that nucleic acid-based vaccines may produce epitopes with different glycosylations from other types of vaccine, resulting in different immune responses. As it is widely accepted that the lack of information about protein glycosylation hampers the design or compromises the efficacy of vaccines (Wolfert and Boons, 2013), glycosylation of $S$ protein should be taken into consideration in the development of SARS-CoV-2 vaccines.

Glycans have been well considered in developing HIV broadly neutralizing antibodies (Duan et al., 2018; Escolano et al., 2019; Watanabe et al., 2019; Seabright et al., 2020). By introducing $\mathrm{N}$-linked glycans into non-CD4-binding site surfaces to mask

\section{REFERENCES}

Andersen, K. G., Rambaut, A., Lipkin, W. I., Holmes, E. C., and Garry, R. F. (2020). The proximal origin of SARS-CoV-2. Nat. Med. 26 (4), 450-452. doi:10.1038/ s41591-020-0820-9

Bagdonaite, I., and Wandall, H. H. (2018). Global aspects of viral glycosylation. Glycobiology 28 (7), 443-467. doi:10.1093/glycob/cwy021

Baker, A. N., Richards, S.-J., Guy, C. S., Congdon, T. R., Hasan, M., Zwetsloot, A. J., et al. (2020). The SARS-COV-2 spike protein binds sialic acids and enables rapid detection in a lateral flow point of care diagnostic device. ACS Cent. Sci. 6 (11), 2046-2052. doi:10.1021/ acscentsci.0c00855 irrelevant epitopes, higher proportions of CD4-binding site-specific antibody were produced (Duan et al., 2018), suggesting glycan masking can be used to limit off-target antibody production and increase on-target immune response. Escolano et al. designed an immunogen that recognized the V3glycan patch on the envelope protein of HIV-1 and found this immunogen elicited specific serological responses in mice or macaques (Escolano et al., 2019). In reviewing the current SARS-CoV-2 vaccine candidates, most of them are based on $\mathrm{S}$ peptide epitopes, and glycans are rarely been considered. However, awareness is increasing, and more studies will address the need of relevant glycosylation in SARS-CoV-2 vaccine design. In fact, since studies on inactivated influenza virus and recombinant gp120 of HIV vaccines indicate that glycoengineering of glycan shields to present a-gal epitopes enables antibody for amplifying vaccine efficacy, glycoengineering of a-gal epitopes on SARS-CoV-2 vaccines has been proposed (Galili, 2020). Given the fact that antibody S309 neutralizes both SARS-CoV and SARS-CoV-2, glycan-based vaccine or broad neutralizing antibody against closely related CoVs is promising.

\section{Future Perspectives}

It has long been known that glycosylation of viral envelope proteins is essential for infectivity and affects immune recognition. Here, we briefly summarized the roles of SARSCoV-2 S protein glycans in viral infection and antibody elicitation. With rapidly evolving analytical methods toward glycan determination and increasing awareness of the importance of glycans in virus biology and vaccine design, we will have a complete picture of virus glycosylation, and their roles in viral infection and host immune response.

\section{AUTHOR CONTRIBUTIONS}

$\mathrm{XZ}$ and $\mathrm{HW}$ wrote the manuscript, and $\mathrm{HC}$ and $\mathrm{HW}$ made the figures.

\section{FUNDING}

This work was supported by the National Natural Science Foundation of China (Grant 81871662) and Xi'an Jiaotong University Research fund xzy032020037 and QNXJTU-04.

Behrens, A.-J., Vasiljevic, S., Pritchard, L. K., Harvey, D. J., Andev, R. S., Krumm, S. A., et al. (2016). Composition and antigenic effects of individual glycan sites of a trimeric HIV-1 envelope glycoprotein. Cell Rep. 14 (11), 2695-2706. doi:10. 1016/j.celrep.2016.02.058

Berg, J. B., Tymoczko, J. L., and Stryer, L. (2002). Biochemistry, 5th Edn. New York, NY: W. H. Freeman, 468-469.

Bosch, B. J., van der Zee, R., de Haan, C. A. M., and Rottier, P. J. M. (2003). The coronavirus spike protein is a class I virus fusion protein: structural and functional characterization of the fusion core complex. J. Virol. 77 (16), 8801-8811. doi:10.1128/jvi.77.16.8801-8811.2003

Breitling, J., and Aebi, M. (2013). N-linked protein glycosylation in the endoplasmic reticulum. Cold Spring Harb. Perspect. Biol., 5 (8), a013359. doi:10.1101/cshperspect.a013359 
Brun, J., Vasiljevic, S., Gangadharan, B., Hensen, M., Chandran, A. V., Hill, M. L., et al. (2020). Analysis of SARS-CoV-2 spike glycosylation reveals shedding of a vaccine candidate. bioRxiv. Available at: https://www.biorxiv.org/content/10. 1101/2020.11.16.384594v1.full (Acessed November 16, 2020).

Buchacher, A., Predl, R., Strutzenberger, K., Steinfellner, W., Trkola, A., Purtscher, M., et al. (1994). Generation of human monoclonal antibodies against HIV-1 proteins; electrofusion and Epstein-Barr virus transformation for peripheral blood lymphocyte immortalization. AIDS Res. Hum. Retrovir. 10 (4), 359-369. doi:10.1089/aid.1994.10.359

Butler, D. L., and Gildersleeve, J. C. (2020). Abnormal antibodies to selfcarbohydrates in SARS-CoV-2 infected patients. bioRxiv 2020341479. doi:10.1101/2020.10.15.341479

Cao, Y., Su, B., Guo, X., Sun, W., Deng, Y., Bao, L., et al. (2020). Potent neutralizing antibodies against SARS-CoV-2 identified by high-throughput single-cell sequencing of convalescent patients' B cells. Cell 182 (1), 73-84.e16. doi:10. 1016/j.cell.2020.05.025

Casalino, L., Gaieb, Z., Goldsmith, J. A., Hjorth, C. K., Dommer, A. C., Harbison, A. M., et al. (2020). Beyond shielding: the roles of glycans in the SARS-CoV-2 spike protein. ACS Cent. Sci. 6, 1722-1734. doi:10.1021/acscentsci.0c01056

Conte, C., Sogni, F., Affanni, P., Veronesi, L., Argentiero, A., and Esposito, S. (2020). Vaccines against coronaviruses: the State of the art. Vaccines 8 (2), 309. doi:10.3390/vaccines8020309

Coronaviridae Study Group of the International Committee on Taxonomy of Viruses (2020). The species Severe acute respiratory syndrome-related coronavirus: classifying $2019-\mathrm{nCoV}$ and naming it SARS-CoV-2. Nat. Microbiol. 5 (4), 536-544. doi:10.1038/s41564-020-0695-Z

Cui, J., Li, F., and Shi, Z.-L. (2019). Origin and evolution of pathogenic coronaviruses. Nat. Rev. Microbiol. 17 (3), 181-192. doi:10.1038/s41579-0180118-9

Doores, K. J. (2015). The HIV glycan shield as a target for broadly neutralizing antibodies. FEBS J. 282 (24), 4679-4691. doi:10.1111/febs.13530

Duan, H., Chen, X., Boyington, J. C., Cheng, C., Zhang, Y., Jafari, A. J., et al. (2018). Glycan masking focuses immune responses to the HIV-1 CD4-binding site and enhances elicitation of VRC01-class precursor antibodies. Immunity 49 (2), 301-311.e5. doi:10.1016/j.immuni.2018.07.005

Escolano, A., Gristick, H. B., Abernathy, M. E., Merkenschlager, J., Gautam, R., Oliveira, T. Y., et al. (2019). Immunization expands B cells specific to HIV-1 V3 glycan in mice and macaques. Nature 570 (7762), 468-473. doi:10.1038/s41586019-1250-z

Falkowska, E., Kajumo, F., Garcia, E., Reinus, J., and Dragic, T. (2007). Hepatitis C virus envelope glycoprotein E2 glycans modulate entry, CD81 binding, and neutralization. J. Virol. 81 (15), 8072-8079. doi:10.1128/jvi.00459-07

Falkowska, E., Le, K. M., Ramos, A., Doores, K. J., Lee, J. H., Blattner, C., et al. (2014). Broadly neutralizing HIV antibodies define a glycan-dependent epitope on the prefusion conformation of gp41 on cleaved envelope trimers. Immunity 40 (5), 657-668. doi:10.1016/j.immuni.2014.04.009

Fantini, J., Chahinian, H., and Yahi, N. (2020). Leveraging coronavirus binding to gangliosides for innovative vaccine and therapeutic strategies against COVID19. Biochem. Biophys. Res. Commun. 538, 132-136. doi:10.1016/j.bbrc.2020. 10.015

Finlay, B. B., and McFadden, G. (2006). Anti-immunology: evasion of the host immune system by bacterial and viral pathogens. Cell 124 (4), 767-782. doi:10. 1016/j.cell.2006.01.034

Fung, T. S., and Liu, D. X. (2018). Post-translational modifications of coronavirus proteins: roles and function. Future Virol. 13 (6), 405-430. doi:10.2217/ful2018-0008

Galili, U. (2020). Amplifying immunogenicity of prospective covid-19 vaccines by glycoengineering the coronavirus glycan-shield to present a-gal epitopes. Vaccine 38 (42), 6487-6499. doi:10.1016/j.vaccine.2020.08.032

Gerken, T. A., Jamison, O., Perrine, C. L., Collette, J. C., Moinova, H., Ravi, L., et al. (2011). Emerging paradigms for the initiation of mucin-type protein O-glycosylation by the polypeptide GalNAc transferase family of glycosyltransferases. J. Biol. Chem. 286 (16), 14493-14507. doi:10.1074/jbc. $\mathrm{m} 111.218701$

Grant, O. C., Montgomery, D., Ito, K., and Woods, R. J. (2020). Analysis of the SARS-CoV-2 spike protein glycan shield reveals implications for immune recognition. Sci. Rep. 10 (1), 14991. doi:10.1038/s41598-020-71748-7
Gui, M., Song, W., Zhou, H., Xu, J., Chen, S., Xiang, Y., et al. (2017). Cryo-electron microscopy structures of the SARS-CoV spike glycoprotein reveal a prerequisite conformational state for receptor binding. Cell Res. 27 (1), 119-129. doi:10. $1038 /$ cr.2016.152

Hao, W., Ma, B., Li, Z., Wang, X., Gao, X., Li, Y., et al. (2020). Binding of the SARSCoV-2 spike protein to glycans. bioRxiv. Available at: https://www.biorxiv.org/ content/10.1101/2020.05.17.100537v1 (Accessed January 19, 2021).

Hasöksüz, M., Kiliç, S., and Saraç, F. (2020). Coronaviruses and SARS-COV-2. Turk J. Med. Sci. 50 (SI-1), 549-556. doi:10.3906/sag-2004-127

Hoffmann, M., Kleine-Weber, H., Schroeder, S., Krüger, N., Herrler, T., Erichsen, S., et al. (2020). SARS-CoV-2 cell entry depends on ACE2 and TMPRSS2 and is blocked by a clinically proven protease inhibitor. Cell 181 (2), 271-280.e8. doi:10.1016/j.cell.2020.02.052

Hu, B., Guo, H., Zhou, P., and Shi, Z. L. (2020). Characteristics of SARS-CoV-2 and COVID-19. Nat. Rev. Microbiology 19, 141-154. doi:10.1038/s41579-02000459-7

Iraqi, M., Edri, A., Greenshpan, Y., Kundu, K., Bolel, P., Cahana, A., et al. (2020). $\mathrm{N}$-glycans mediate the ebola virus-GP1 shielding of ligands to immune receptors and immune evasion. Front. Cell Infect. Microbiol. 10, 48. doi:10. $3389 /$ fcimb. 2020.00048

Johnson, B. A., Xie, X., Kalveram, B., Lokugamage, K. G., Muruato, A., Zou, J., et al. (2020). Furin cleavage site is key to SARS-CoV-2 pathogenesis. bioRxiv 2020, 268854. doi:10.1101/2020.08.26.268854

Ju, B., Zhang, Q., Ge, J., Wang, R., Sun, J., Ge, X., et al. (2020). Human neutralizing antibodies elicited by SARS-CoV-2 infection. Nature 584 (7819), 115-119. doi:10.1038/s41586-020-2380-z

Kappler, K., and Hennet, T. (2020). Emergence and significance of carbohydratespecific antibodies. Genes Immun. 21 (4), 224-239. doi:10.1038/s41435-0200105-9

Kirchdoerfer, R. N., Cottrell, C. A., Wang, N., Pallesen, J., Yassine, H. M., Turner, H. L., et al. (2016). Pre-fusion structure of a human coronavirus spike protein. Nature 531 (7592), 118-121. doi:10.1038/nature17200

Koehler, M., Delguste, M., Sieben, C., Gillet, L., and Alsteens, D. (2020). Initial step of virus entry: virion binding to cell-surface glycans. Annu. Rev. Virol. 7 (1), 143-165. doi:10.1146/annurev-virology-122019-070025

Lan, J., Ge, J., Yu, J., Shan, S., Zhou, H., Fan, S., et al. (2020). Structure of the SARS$\mathrm{CoV}-2$ spike receptor-binding domain bound to the ACE2 receptor. Nature 581 (7807), 215-220. doi:10.1038/s41586-020-2180-5

Lederer, K., Castaño, D., Gómez Atria, D., Oguin, T. H., Wang, S., Manzoni, T. B., et al. (2020). SARS-CoV-2 mRNA vaccines foster potent antigen-specific germinal center responses associated with neutralizing antibody generation. Immunity 53 (6), 1281-1295.e5. doi:10.1016/j.immuni.2020.11.009

Lenza, M. P., Oyenarte, I., Diercks, T., Quintana, J. I., Gimeno, A., Coelho, H., et al. (2020). Structural characterization of N-linked glycans in the receptor binding domain of the SARS-CoV-2 spike protein and their interactions with human lectins. Angew. Chem. Int. Ed. 59 (52), 23763-23771. doi:10.1002/anie. 202011015

Li, F. (2016). Structure, function, and evolution of coronavirus spike proteins. Annu. Rev. Virol. 3 (1), 237-261. doi:10.1146/annurev-virology-110615042301

Li, W., Hulswit, R. J. G., Widjaja, I., Raj, V. S., McBride, R., Peng, W., et al. (2017). Identification of sialic acid-binding function for the Middle East respiratory syndrome coronavirus spike glycoprotein. Proc. Natl. Acad. Sci. U.S.A. 114 (40), E8508-E8517. doi:10.1073/pnas.1712592114

Liu, L., Chopra, P., Li, X., Wolfert, M. A., Tompkins, S. M., and Boons, G. J. (2020). SARS-CoV-2 spike protein binds heparan sulfate in a length- and sequencedependent manner. BioRxiv 2020, 087288. doi:10.1101/2020.05.10.087288

Mouquet, H., Scharf, L., Euler, Z., Liu, Y., Eden, C., Scheid, J. F., et al. (2012). Complex-type $\mathrm{N}$-glycan recognition by potent broadly neutralizing HIV antibodies. Proc. Natl. Acad. Sci. U.S.A. 109 (47), E3268-E3277. doi:10.1073/ pnas. 1217207109

Murin, C. D., Wilson, I. A., and Ward, A. B. (2019). Antibody responses to viral infections: a structural perspective across three different enveloped viruses. Nat. Microbiol. 4 (5), 734-747. doi:10.1038/s41564-019-0392-y

Ou, X., and Liu, Y., Lei, X., Li, P., Mi, D., Ren, L., et al. (2020). Characterization of spike glycoprotein of SARS-CoV-2 on virus entry and its immune cross-reactivity with SARS-CoV. Nat. Commun. 11 (1), 1620. doi:10.1038/s41467-020-15562-9 
Pallesen, J., Wang, N., Corbett, K. S., Wrapp, D., Kirchdoerfer, R. N., Turner, H. L., et al. (2017). Immunogenicity and structures of a rationally designed prefusion MERS-CoV spike antigen. Proc. Natl. Acad. Sci. U.S.A. 114 (35), E7348-E7357. doi:10.1073/pnas.1707304114

Pancera, M., Shahzad-ul-Hussan, S., Doria-Rose, N. A., McLellan, J. S., Bailer, R. T., Dai, K., et al. (2013). Structural basis for diverse N-glycan recognition by HIV1-neutralizing V1-V2-directed antibody PG16. Nat. Struct. Mol. Biol. 20 (7), 804-813. doi:10.1038/nsmb.2600

Patel, P., and Kearney, J. F. (2016). Immunological outcomes of antibody binding to glycans shared between microorganisms and mammals. J. Immunol. 197 (11), 4201-4209. doi:10.4049/jimmunol.1600872

Peng, G., Sun, D., Rajashankar, K. R., Qian, Z., Holmes, K. V., and Li, F. (2011). Crystal structure of mouse coronavirus receptor-binding domain complexed with its murine receptor. Proc. Natl. Acad. Sci. U.S.A. 108 (26), 10696-10701. doi:10.1073/pnas.1104306108

Peng, G., Xu, L., Lin, Y.-L., Chen, L., Pasquarella, J. R., Holmes, K. V., et al. (2012). Crystal structure of bovine coronavirus spike protein lectin domain. J. Biol. Chem. 287 (50), 41931-41938. doi:10.1074/jbc.m112.418210

Pinto, D., Park, Y.-J., Beltramello, M., Walls, A. C., Tortorici, M. A., Bianchi, S., et al. (2020). Cross-neutralization of SARS-CoV-2 by a human monoclonal SARS-CoV antibody. Nature 583 (7815), 290-295. doi:10.1038/s41586-0202349-y

Raman, R., Tharakaraman, K., Sasisekharan, V., and Sasisekharan, R. (2016). Glycan-protein interactions in viral pathogenesis. Curr. Opin. Struct. Biol. 40, 153-162. doi:10.1016/j.sbi.2016.10.003

Ravichandran, S., Coyle, E. M., Klenow, L., Tang, J., Grubbs, G., Liu, S., et al. (2020). Antibody signature induced by SARS-CoV-2 spike protein immunogens in rabbits. Sci. Transl. Med. 12 (550), eabc3539. doi:10.1126/scitranslmed.abc3539

Robson, B. (2020). Bioinformatics studies on a function of the SARS-CoV-2 spike glycoprotein as the binding of host sialic acid glycans. Comput. Biol. Med. 122, 103849. doi:10.1016/j.compbiomed.2020.103849

Rouse, B. T., and Sehrawat, S. (2010). Immunity and immunopathology to viruses: what decides the outcome? Nat. Rev. Immunol. 10 (7), 514-526. doi:10.1038/ nri2802

Rouvinski, A., Guardado-Calvo, P., Barba-Spaeth, G., Duquerroy, S., Vaney, M.-C., Kikuti, C. M., et al. (2015). Recognition determinants of broadly neutralizing human antibodies against dengue viruses. Nature 520 (7545), 109-113. doi:10. 1038/nature14130

Sanda, M., Morrison, L., and Goldman, R. (2020). N and O glycosylation of the SARS-CoV-2 spike protein. bioRxiv.Available at: https://www.biorxiv.org/ content/10.1101/2020.07.05.187344v1 (Accessed July 6, 2020).

Scanlan, C. N., Pantophlet, R., Wormald, M. R., Ollmann Saphire, E., Stanfield, R., Wilson, I. A., et al. (2002). The broadly neutralizing anti-human immunodeficiency virus type 1 antibody $2 \mathrm{G} 12$ recognizes a cluster of $\alpha 1 \rightarrow 2$ mannose residues on the outer face of gp120. J. Virol. 76 (14), 7306-7321. doi:10.1128/jvi.76.14.7306-7321.2002

Seabright, G. E., Cottrell, C. A., van Gils, M. J., D’addabbo, A., Harvey, D. J., Behrens, A.-J., et al. (2020). Networks of HIV-1 envelope glycans maintain antibody epitopes in the face of glycan additions and deletions. Structure 28 (8), 897-909.e6. doi:10.1016/j.str.2020.04.022

Shajahan, A., Supekar, N. T., Gleinich, A. S., and Azadi, P. (2020). Deducing the Nand O- glycosylation profile of the spike protein of novel coronavirus SARSCoV-2. Glycobiology 30, cwaa101. doi:10.1093/glycob/cwaa101

Sternberg, A., and Naujokat, C. (2020). Structural features of coronavirus SARSCoV-2 spike protein: targets for vaccination. Life Sci. 257, 118056. doi:10.1016/j. lfs.2020.118056

Stewart-Jones, G. B. E., Soto, C., Lemmin, T., Chuang, G.-Y., Druz, A., Kong, R., et al. (2016). Trimeric HIV-1-Env structures define glycan shields from clades A, B, and G. Cell 165 (4), 813-826. doi:10.1016/j.cell.2016.04.010

Tortorici, M. A., Walls, A. C., Lang, Y., Wang, C., Li, Z., Koerhuis, D., et al. (2019). Structural basis for human coronavirus attachment to sialic acid receptors. Nat. Struct. Mol. Biol. 26 (6), 481-489. doi:10.1038/s41594-019$0233-y$

Trkola, A., Purtscher, M., Muster, T., Ballaun, C., Buchacher, A., Sullivan, N., et al. (1996). Human monoclonal antibody 2 G12 defines a distinctive neutralization epitope on the gp120 glycoprotein of human immunodeficiency virus type 1 . J. Virol. 70 (2), 1100-1108. doi:10.1128/jvi.70.2.1100-1108.1996

Virology (1968). Virology: coronaviruses. Nature 220 (5168), 650. doi:10.1038/ $220650 \mathrm{~b} 0$

Walls, A. C., Park, Y.-J., Tortorici, M. A., Wall, A., McGuire, A. T., and Veesler, D. (2020). Structure, function, and antigenicity of the SARS-CoV-2 spike glycoprotein. Cell 181 (2), 281-292.e6. doi:10.1016/j.cell.2020.02.058

Walls, A. C., Xiong, X., Park, Y.-J., Tortorici, M. A., Snijder, J., Quispe, J., et al. (2019). Unexpected receptor functional mimicry elucidates activation of coronavirus fusion. Cell 176 (5), 1026-1039.e15. doi:10.1016/j.cell.2018. 12.028

Wang, D. (2020). Coronaviruses' sugar shields as vaccine candidates. Curr. Trends Immunol. 21, 17-23.

Wang, D., Tang, J., Tang, J., and Wang, L.-X. (2015). Targeting N-glycan cryptic sugar moieties for broad-spectrum virus neutralization: progress in identifying conserved molecular targets in viruses of distinct phylogenetic origins. Molecules 20 (3), 4610-4622. doi:10.3390/molecules 20034610

Watanabe, Y., Allen, J. D., Wrapp, D., McLellan, J. S., and Crispin, M. (2020). Sitespecific glycan analysis of the SARS-CoV-2 spike. Science 369 (6501), 330-333. doi:10.1126/science.abb9983

Watanabe, Y., Bowden, T. A., Wilson, I. A., and Crispin, M. (2019). Exploitation of glycosylation in enveloped virus pathobiology. Biochim. Biophys. Acta Gen. Subj. 1863 (10), 1480-1497. doi:10.1016/j.bbagen.2019.05.012

Wolfert, M. A., and Boons, G. J. (2013). Adaptive immune activation: glycosylation does matter. Nat. Chem. Biol. 9 (12), 776-784. doi:10.1038/nchembio.1403

Wrapp, D., Wang, N., Corbett, K. S., Goldsmith, J. A., Hsieh, C. L., Abiona, O., et al. (2020). Cryo-EM structure of the 2019-nCoV spike in the prefusion conformation. Science 367, 1260-1263. doi:10.1126/science.abb2507

Xia, S., Lan, Q., Su, S., Wang, X., Xu, W., Liu, Z., et al. (2020). The role of furin cleavage site in SARS-CoV-2 spike protein-mediated membrane fusion in the presence or absence of trypsin. Signal Transduct. Target Ther. 5 (1), 92. doi:10. 1038/s41392-020-0184-0

Yan, R., Zhang, Y., Li, Y., Xia, L., Guo, Y., and Zhou, Q. (2020). Structural basis for the recognition of SARS-CoV-2 by full-length human ACE2. Science 367 (6485), 1444-1448. doi:10.1126/science.abb2762

Yuan, Y., Cao, D., Zhang, Y., Ma, J., Qi, J., Wang, Q., et al. (2017). Cryo-EM structures of MERS-CoV and SARS-CoV spike glycoproteins reveal the dynamic receptor binding domains. Nat. Commun. 8, 15092. doi:10.1038/ ncomms 15092

Zhao, P., Praissman, J. L., Grant, O. C., Cai, Y., Xiao, T., Rosenbalm, K. E., et al. (2020). Virus-receptor interactions of glycosylated SARS-CoV-2 spike and human ACE2 receptor, Cell Host Microb. 28 (4), 586-601.e6. doi:10.1016/j. chom.2020.08.004

Zhou, P., Yang, X.-L., Wang, X.-G., Hu, B., Zhang, L., Zhang, W., et al. (2020). A pneumonia outbreak associated with a new coronavirus of probable bat origin. Nature 579 (7798), 270-273. doi:10.1038/s41586-020-2012-7

Conflict of Interest: The authors declare that the research was conducted in the absence of any commercial or financial relationships that could be construed as a potential conflict of interest.

Copyright $\odot 2021$ Zhao, Chen and Wang. This is an open-access article distributed under the terms of the Creative Commons Attribution License (CC BY). The use, distribution or reproduction in other forums is permitted, provided the original author(s) and the copyright owner(s) are credited and that the original publication in this journal is cited, in accordance with accepted academic practice. No use, distribution or reproduction is permitted which does not comply with these terms. 